\title{
Terapia comunitária como recurso de abordagem do problema do abuso do álcool, na atenção primária
}

\author{
Francinete Alves de Oliveira Giffoni ${ }^{1}$ \\ Manoel Antônio dos Santos ${ }^{2}$
}

\begin{abstract}
Este estudo teve por objetivo identificar potencialidades da terapia comunitária (TC) como recurso de abordagem do problema do abuso do álcool na atenção primária, sob a perspectiva de um usuário. A pesquisa foi realizada na sede do Projeto Quatro Varas, Fortaleza, CE. Empregou-se a abordagem qualitativa de cunho etnográfico, utilizando entrevista semiestruturada e observação participante. Dos 20 participantes da terapia entrevistados, um foi escolhido para entrevista de aprofundamento. Construíram-se dois núcleos temáticos: os efeitos da terapia na abordagem do alcoolismo e terapia como recurso de apoio social, na abordagem dos problemas relacionados ao uso de álcool. Resultados indicam que o diálogo estabelecido na terapia promove ressignificação da problemática e redirecionamento de itinerários terapêuticos, no sentido da gestão da própria vida e busca da cidadania. Conclui-se que a TC favorece a formação de teia de relações sistêmicas, que amplia a compreensão dos problemas decorrentes do uso de álcool, constituindo-se em efetiva estratégia para sua abordagem no campo da saúde comunitária.
\end{abstract}

Descritores: Terapêutica; Redes Comunitárias; Apoio Social; Grupos de Auto-Ajuda; Alcoolismo; Transtornos Relacionados ao Uso de Álcool.

\footnotetext{
1 Médica Psiquiatra. Professor Doutor, Universidade Federal do Ceará, Fortaleza, CE, Brasil. E-mail: francinetealves@gmail.com.

${ }^{2}$ Psicólogo, Doutor em Psicologia. Professor Doutor, Faculdade de Filosofia, Ciências e Letras de Ribeirão Preto, Universidade de São Paulo, SP, Brasil. E-mail: masantos@ffclrp.usp.br.
}

Correspondencia:

Manoel Antônio dos Santos

Universidade de São Paulo. Faculdade de Filosofia, Ciências e Letras de Ribeirão Preto.

Av. dos Bandeirantes, 3900

Bairro: Monte Alegre

CEP: 14040-902 Ribeirão Preto, SP, Brasil

E-mail: masantos@ffclrp.usp.br 


\section{Terapia comunitaria como medio de abordar el problema del abuso de alcohol en la atención primaria}

Este estudio tuvo como objetivo identificar el potencial de la terapia comunitaria (TC) como medio de abordar el problema del abuso de alcohol en la atención primaria desde la perspectiva del usuario. La investigación fue realizada en la Sede del Proyecto Cuatro Varas, Fortaleza-CE, Brasil. Fue empleado un abordaje cualitativo de tipo etnográfico, utilizando la entrevista semiestructurada y la observación participante. De los 20 participantes de la terapia entrevistados, uno fue escogido para la entrevista en profundidad. Construimos dos núcleos temáticos: los efectos de la terapia en el abordaje del alcoholismo y la terapia como recurso de apoyo social en el abordaje de los problemas relacionados al uso de alcohol. Los resultados indican que el diálogo establecido en la terapia promueve resignificación de la problemática y reorientación de itinerarios terapéuticos en el sentido de la gestión de la propia vida y la búsqueda de la ciudadanía. Concluimos que la TC favorece la formación de una red de relaciones sistémicas, que amplia la comprensión de los problemas provenientes del uso de alcohol, constituyéndose en efectiva estrategia para su abordaje en el campo de la salud comunitaria.

Descriptores: Terapêutica; Redes Comunitarias; Apoyo Social; Grupos de Autoayuda; Alcoholismo; Trastornos Relacionados con Alcohol.

\section{Community Therapy as a Method to Address the Problem of Alcohol Abuse in Primary Care}

This study aimed to identify the potential of community therapy (CT) as a method to address the problem of alcohol abuse in primary care from a user perspective. This study was carried out at the headquarters of the Quatro Varas Project, Fortaleza$\mathrm{CE}$, Brazil. This qualitative, ethnographic study used semi-structured interview and participant observation. Of the 20 interviewed participants, one was chosen for an indepth interview. Two thematic units were constructed: the effects of the therapy on alcoholism and therapy as a social support resource for problems related to alcohol use. Results indicate that the dialogue established during therapy promotes re-signification of the problem and redirects the therapy course towards management of one's own life and search for citizenship. We concluded that CT favors the elaboration of a network of systemic relationships that broaden the understanding of problems caused by alcoholism and is an effective strategy to address the problem in the community health sphere.

Descriptors: Therapeutics; Community Networks; Social Support; Self-Help Groups; Alcoholism; Alcohol-Related Disorders.

\section{Introdução}

Entende-se, atualmente, que o fenômeno das drogas se insere no âmbito da saúde coletiva, com abrangência nacional e internacional, e que se relaciona a complexa trama de fatores biopsicossociais. Estudos recentes indicam que as medidas de combate e controle devem ser associadas a ações multidisciplinares de prevenção e promoção da saúde, nos níveis individual, familiar e coletivo(1). O aumento da produção, comercialização e consumo de drogas lícitas e ilícitas é fenômeno sistêmico que deve ser compreendido no contexto da emergência de fatores globais, como a ampliação do fluxo de comércio de bens e serviços na era da globalização, viagens transnacionais, sofisticação dos meios de comunicação de massa e avanços tecnológicos. Combinados, esses fatores potencializam os padrões de consumo de forma geral, incluindo o uso de substâncias 
psicoativas, acentuando outros problemas associados à explosão populacional, como violência e criminalidade. Esses problemas causam enormes preocupações aos governos e prejuízos à sociedade civil.

Nos últimos anos, nota-se crescimento da produção científica na área de álcool e/ou outras drogas. No âmbito nacional, diversos estudos têm sido publicados, relatando situações de sofrimento, consequentes ao abuso de álcool e outras drogas ${ }^{(1-6)}$.

No campo da terapêutica para os problemas derivados do abuso do álcool e outras substâncias psicoativas, uma das abordagens mais promissoras é a terapia comunitária (TC). Trata-se de modalidade terapêutica nascida na favela do Pirambu, em Fortaleza, CE, no ano 1987, e que tem sido incorporada como política pública do Sistema Único de Saúde (SUS), difundindo-se para todos os Estados do Brasil, alguns países da Europa e EUA ${ }^{(7)}$. Estudos recentes têm sido dedicados a demonstrar as bases teóricas e os benefícios terapêuticos de sua aplicação(8), bem como as repercussões dessa modalidade de tratamento, no cotidiano de seus participantes ${ }^{(9)}$.

A trajetória nesse campo começou quando a autoria deste estudo contatou com esse contexto de atenção primária para desenvolver tese de doutorado. Tomou-se conhecimento do Projeto Quatro Varas, projeto de extensão do Departamento de Saúde Comunitária da Universidade Federal do Ceará (UFC) que oferece assistência a pessoas com diferentes tipos de sofrimento, dentre os quais os suscitados pelos problemas relacionados ao uso abusivo do álcool. Tão logo se adentrou nesse local, o ambiente propiciava sentir-se à vontade na palhoça rústica onde acontece a terapia. Ali houve o acolhimento hospitaleiro das pessoas da comunidade. O modo simples de falar, os traços da cultura nordestina, na qual a autoria também tem raízes culturais, eram aspectos que facilitavam a imersão no campo de pesquisa. Porém, o que determinou o real interesse pelo Projeto Quatro Varas foi encontrar abordagem médico-antropológica ao sofrimento humano, baseada no diálogo entre o conhecimento científico e o saber popular.

A valorização dos saberes populares pela TC fez renascer a esperança em medicina mais humanizada e dedicada às aflições da maior parte da população. A disposição das pessoas em círculo, a oportunidade que todas têm de falar e serem ouvidas, a liderança democrática de um facilitador do processo grupal e a diversidade dos participantes, que incluíam pessoas da comunidade local e visitantes de variados níveis educacionais e camadas sociais, guardavam similaridades com as experiências do círculo de culturas ${ }^{(10)}$, método de alfabetização de adultos que opera por meio da discussão de temas relacionados à cultura e ao cotidiano, de que se tinha conhecimento anterior, e com o qual havia identificação. Desde então, houve interesse em aprofundar os conhecimentos na TC.

O leque de aplicabilidade da TC é amplo, podendo funcionar como recurso de atenção primária, visando a prevenção de problemas ou seu agravamento, assim como se presta ao tratamento de dificuldades já instaladas, como o uso de substâncias psicoativas. A riqueza das práticas populares de cura é valorizada e incorporada pela TC, consoante com compreensão mais próxima dos aspectos culturais envolvidos no processo saúde/doença. Nesse sentido, para condução do estudo, elegeu-se a abordagem etnográfica, entendendo que essa perspectiva permite compreender um universo de culturas e horizontes diferentes do mundo habitual, no qual, nós, humanos, nos movemos. Foi nesse contexto que se começou a vislumbrar as possibilidades de poder exercitar o "estranhamento" necessário para investigar a TC, no enfoque etnográfico.

Neste estudo, buscaram-se as potencialidades da TC como abordagem terapêutica e preventiva ao fenômeno das drogas, no campo da saúde comunitária, tentando identificar se esse enfoque contribui para promover ressignificações, tanto do ponto de vista individual como coletivo, acerca do uso de álcool. Mais especificamente, procurou-se delinear se as estratégias utilizadas na terapia contribuem para o redirecionamento de itinerários terapêuticos no sentido da reinserção social de seus participantes e do fortalecimento da cidadania. Desse modo, identificaram-se potenciais contribuições da TC para a elaboração de políticas públicas na área do tratamento. A busca bibliográfica revelou inexistência de estudos que tenham se debruçado sobre essas questões, na perspectiva da TC, especialmente no que se refere à utilização dessa modalidade de terapia no tratamento do abuso do álcool e/ou de outras drogas.

No enfoque da saúde comunitária, substâncias psicoativas são compreendidas como fenômeno de natureza psicossocial, o que inclui dimensões muito mais amplas do que a tradicional abordagem anatomoclínica do problema. Essa concepção assimila a percepção do abuso de álcool e/ou de outras drogas como questão social e cultural, com implicações nas áreas da medicina, enfermagem, psicologia, sociologia, antropologia, saúde pública, direito e ética.

O contato intenso e prolongado com o campo de investigação conduziu a uma série de indagações: 
até que ponto a TC modifica as concepções de seus participantes sobre o uso de álcool e/ou outras drogas? De que modo a participação na TC estaria favorecendo a ressignificação da problemática das drogas, redirecionando os itinerários terapêuticos no sentido da busca de autonomia e reinserção social? A abordagem da problemática das drogas na TC estaria contribuindo para sua percepção como temática pertinente ao campo da saúde comunitária?

Ao considerar a importância e atualidade dessas questões, este estudo teve por objetivo identificar as potencialidades da terapia comunitária (TC) como recurso de abordagem do problema do uso abusivo do álcool, na atenção primária, sob a perspectiva de um usuário.

\section{Percurso metodológico}

Escolheu-se a abordagem etnográfica como referencial metodológico, a partir da observação participante e da técnica da entrevista semiestruturada.

Enquanto eram analisados os resultados da pesquisa de doutorado, percebeu-se que a TC proporcionava processo de aprendizagem de competências sociais, como o desenvolvimento de capacidade de liderança e autonomia, estimulando seus frequentadores a incluír em seus objetivos terapêuticos, além da cura ou alívio de seus problemas emocionais, a conquista da plena cidadania. Nesse percurso, frequentemente deparavase com relatos de problemas direta ou indiretamente relacionados ao uso do álcool e/ou outras drogas, muito comumente encontrados nas zonas de periferia dos grandes aglomerados urbanos, como é o caso do Pirambu, uma das maiores favelas do município de Fortaleza, CE. Com base no relato dessas experiências, decidiu-se investigar as potencialidades da aplicação da TC em indivíduos que faziam uso nocivo de álcool.

$\mathrm{Na}$ abordagem etnográfica, para a delimitação do objeto e dos objetivos do estudo, é fundamental a experiência que, lentamente, o pesquisadorvai adquirindo no trabalho de campo. Na medida em que houve melhor delineamento daquilo que se iria aprofundar na presente investigação, o objeto pôde ser gradualmente definido, juntamente com os objetivos, a partir das inúmeras discussões com outros pesquisadores, ao longo do percurso da construção do trabalho.

O processo de coleta de dados se deu de acordo com o princípio de que, na escolha da estratégia de pesquisa, é fundamental que o método seja adequado ao problema proposto, levando em conta, além do objeto de estudo e dos objetivos do pesquisador, o contexto cultural no qual a realidade investigada está inserida(11). Nesse sentido, o fator mais importante é a adequação entre o problema a ser estudado e a forma de abordálo. Por essa razão, utilizou-se a abordagem etnográfica para alcançar os objetivos, fundamentada em teóricos da antropologia interpretativa(12-13).

Constituiu-se o corpus de análise transcrições de entrevistas semiestrututuradas, realizadas com os participantes da TC, entre os anos 2006 e 2007, nas quais foram relatados problemas que eram, direta ou indiretamente, relacionados ao uso de álcool e/ou de outras drogas. Os relatos transcritos das entrevistas foram complementados pelas anotações do diário de campo, elaborado no decorrer da observação participante. No presente estudo, foram utilizados os dados obtidos com um dos participantes, escolhido com o propósito de aprofundar a análise. De acordo com os pressupostos da abordagem etnográfica, coleta e análise foram realizadas de maneira articulada, na medida em que aconteciam.

O projeto foi aprovado pelo Comitê de Ética em Pesquisa (COMEPE), da Universidade Federal do Ceará, por meio do Ofício n628/06, Protocolo n¹92/96, de acordo com as normas definidas pela Resolução n¹96/96 do Conselho Nacional de Saúde, que regulamenta a pesquisa com seres humanos.

o primeiro passo da pesquisa de campo foi a observação de sessões da terapia. Nesse percurso, foram observadas 24 sessões. Nas primeiras observações houve um pouco mais de dificuldade para manter o distanciamento que faz parte da postura de pesquisador, uma vez que já se conhecía o Projeto Quatro Varas há mais de 10 anos, tendo participado, a convite de seu idealizador, de várias sessões. Por esse motivo, além de se estar atento para executar rigorosamente os procedimentos da pesquisa, havia a preocupação de substituir o olhar habitual pelo "estranhamento"(14), que foi adquirido aos poucos.

Outro cuidado que se teve foi evitar que outros referenciais trazidos da trajetória profissional interferissem no processo de interpretação dos achados. Para minimizar o risco de vieses, anotava-se com cuidado as observações no diário de campo, fazendo registros detalhados das percepções, guiando-se pelo referencial etnográfico. Nessa perspectiva, concebeuse que não há separação radical entre sujeito e objeto de estudo. Ambos têm substrato comum que os tornam solidariamente imbricados e comprometidos(15). Por isso, é importante buscar preservar ao máximo o ponto de vista dos interlocutores e os pressupostos que fundamentam 
a TC, como abordagem que organiza todo um sistema de práticas de cura e atividades socioeducativas, no âmbito do Projeto Quatro Varas. Nesta investigação, levou-se em conta o ritual da terapia e procurou-se compreender o conjunto de práticas e elementos simbólicos que a estruturam, quando a autoria se propôs descrever, cientificamente, e interpretar seus efeitos na vida dos participantes, por meio de suas falas e comportamentos observáveis.

Após observarem-se as sessões de terapia, conversava-se informalmente com vários participantes e terapeutas facilitadores. Dentre os participantes escolheu-se, por conveniência, 20 pessoas para serem entrevistadas, de acordo com os seguintes critérios: aqueles que conheciam a terapia há mais tempo, que frequentavam mais assiduamente as sessões e que se mostraram dispostos a colaborar voluntariamente desta pesquisa. Eram pessoas de ambos os sexos, com atividades ocupacionais diversificadas, a maioria proveniente do próprio bairro e pertencente às camadas sociais mais desfavorecidas. As idades variaram entre 27 e 65 anos. O nível de escolaridade predominante foi o ensino fundamental incompleto.

As entrevistas foram precedidas de conversa preparatória, na qual os objetivos da pesquisa foram explicitados e os locais e horários foram combinados, conforme a conveniência dos entrevistados. Utilizou-se roteiro de entrevista composto por questões norteadoras, com o intuito de facilitar a rememoração dos motivos pelos quais haviam procurado a terapia - buscavase investigar a presença de uso abusivo do álcool e/ ou de outras drogas, como tomaram conhecimento da TC e possíveis transformações pelas quais passaram no decorrer do tempo em que frequentaram as sessões. No desenvolvimento das entrevistas, novas questões que poderiam surgir eram devidamente exploradas, conforme as condições do momento e o fluir da relação pesquisador/entrevistado. Esse procedimento está em consonância com a noção de que a entrevista semiestruturada deve partir de roteiro com algumas perguntas formuladas a priori, mas que tenham margem de flexibilidade para que o próprio entrevistado possa organizar, dentro delas, seu discurso(11).

As entrevistas foram realizadas no próprio ambiente do projeto, logo após a sessão de terapia, ou em outros horários. Isso é consistente com o pressuposto de que o pesquisador deve buscar o contexto onde ocorrem os comportamentos que interessam à sua investigação, procurando situar os vínculos existentes entre esse contexto e os sentimentos, crenças e valores dos entrevistados.
Quando não era possível esgotar o assunto em um primeiro contato, novo encontro era marcado para dar prosseguimento à coleta de dados. Ficou acertado com os participantes que eles teriam acesso à cópia da transcrição do material a fim de autorizarem ou não sua utilização no estudo. Com alguns dos participantes que se mostravam interessados, e por vezes indagavam sobre algum detalhe da pesquisa, compartilhavam-se as motivações que levaram a se estudar o contexto da terapia. Durante o procedimento das entrevistas, procurou-se estabelecer clima de acolhimento, no qual o entrevistado pudesse se sentir à vontade para tirar dúvidas quando achasse necessário, ou interromper sua fala para evidenciar alguma reflexão, ou pedir para não registrar algum trecho da entrevista que não desejasse tornar público. As falas foram audiogravadas e, posteriormente, transcritas na íntegra e de forma literal. Os nomes dos entrevistados foram substituídos por nomes fictícios.

Paralelamente à realização das entrevistas, comparecia-se regularmente às sessões de terapia, para se realizar a observação participante. Após essa segunda fase da investigação, selecionou-se quatro dentre os 20 entrevistados para a realização das entrevistas de aprofundamento. Essas pessoas foram escolhidas porque relataram, em suas entrevistas, que chegaram à terapia em situações de crise e, após alguns anos participando regularmente das sessões, vivenciaram transformações significativas em suas vidas. Nessa terceira fase, a entrevista foi aberta, permitindo maior imersão na experiência existencial de cada um, tendo em vista que se almejava alcançar a dimensão da intensidade, para além da extensão(16).

Tendo em vista o objetivo do presente estudo, selecionaram-se os relatos de um participante, que será referido por nome fictício, Fernando, que ofereceu descrições densas sobre suas experiências com a TC, na abordagem dos problemas derivados do álcool. Para apreender os significados, examinaram-se os dados obtidos por meio da análise das narrativas. Durante a análise dos dados, procuraou-se destacar indícios que levassem a responder ao objetivo proposto, de modo a compreender se a terapia vinha se constituindo como estratégia de apoio social que contribui para a ressignificação do problema do uso de álcool e o redirecionamento do itinerário terapêutico do participante. Desse modo, manteve-se o foco no ponto de vista desse usuário de álcool, abusivo, acerca do apoio fornecido pela estratégia da TC.

Apresentar-se-á, na sequência, a análise dos relatos que fazem referência à problemática em foco, 
evidenciando como as questões referentes ao uso de álcool foram abordadas na terapia do ponto de vista do participante selecionado.

\section{Resultados e Discussão}

Foram construídos dois núcleos temáticos. No primeiro, contemplaram-se os efeitos da terapia na abordagem do alcoolismo. No segundo recorte, focalizouse a TC como recurso de apoio social na abordagem dos problemas relacionados ao uso abusivo do álcool, na perspectiva do participante.

\section{Efeitos da TC na abordagem do alcoolismo na perspectiva de um participante}

Entrevistou-se Fernando logo após uma sessão de terapia, da qual também a entrevistadora havia participado e que foi marcada pelo depoimento emocionado de uma mãe e um pai que haviam perdido seu filho, morto, ainda jovem, em acidente de moto. A motocicleta que dirigia havia sido abalroada por veículo conduzido em alta velocidade por um motorista alcoolizado. Houve interesse em colher as impressões desse participante, considerando sua história de envolvimento pessoal com o tema. Fernando já era conhecido desde que começara a frequentar a terapia havia pouco mais de um ano. Era muito assíduo às sessões e já havia contado algumas vezes sua história de alcoolismo crônico, motivo pelo qual estava desempregado havia 15 anos. Ele contou que havia parado de beber há três anos, desde que começara a frequentar as reuniões dos Alcoólicos Anônimos (AA) e, em seguida, veio para a terapia a convite de sua companheira.

Houve interesse em indagar como ele estava se sentindo porque se observava que, durante a sessão, ele se mostrava em alguns momentos muito emocionado, chegando a chorar. Como ainda parecia sensibilizado, após o término da sessão, esperou-se um pouco e só depois ocorreu a aproximação. Viu-se que suas mãos ainda tremiam um pouco, mas percebeu-se, também, que ele se dispôs a falar sem resistência aparente. Após cumprimentá-lo, estendendo-lhe a mão, como habitualmente se faz, comentou-se que havíam sido observadas, um pouco, suas reações, durante a sessão e se indagou como estava se sentindo naquele momento. Ele respondeu, com a voz ainda embargada pela intensa emoção sentida, o que segue.

Pra mim essa terapia serviu porque eu tenho visto muito caso aqui de problema por causa de alcoolismo, como essa cena aí, de hoje né, fiquei muito chocado. Um jovem que não tinha nada a ver com alcoolismo, acabou morrendo por causa de outro que bebeu e saiu dirigindo. Eu fiquei muito chocado, da mãe tá falando no assunto a respeito da perda do seu filho, quando ela citava, nas palavras dela, que ele era um menino muito bom e, antes de completar os 18 anos, ele perdeu a vida através de um acidente de moto. Uma pessoa alcoolizada no volante do carro trancou o rapaz, que se acidentou e veio a falecer (chora).

Ao se lembrar da triste cena narrada pela mãe do jovem morto, Fernando não conseguiu conter o choro. E prosseguiu seu relato emocionado apresentando reflexão sobre o significado pessoal que essa experiência de se expor à dor compartilhada por aqueles pais proporcionou a ele.

Eu vejo que tem uma importância muito grande isso aqui, a terapia, porque tem uma sabedoria muito grande, de eu saber na minha vida que o alcoolismo é uma das coisas que mais tá destruindo as vidas das pessoas. A pessoa vai pelo caminho sem ingerir as bebidas e é levado a elas... como o rapaz aí. O outro bebe e passa por cima. Todo mundo sabe que alcoolismo é uma doença, mas as pessoas, a sociedade, não admitem essa doença.

Percebeu-se que, no momento em que o tema do alcoolismo fora trazido para a roda terapêutica, de alguma forma os conflitos pessoais de Fernando foram confrontados. O relato dos pais do rapaz morto trouxera, para o espaço público da terapia temática, o que fazia parte de sua vida e de seu cotidiano.

Eu me senti uma pessoa muito... muito emocionada (chora novamente) por aquela colocação da mãe, muito triste, e o pai, por ter perdido o filho dessa forma.

Fernando pôde entrar em contato emocional com questões relacionadas ao uso abusivo do álcool com as quais até então talvez não tenha tido oportunidade de encarar de frente, como o dano provocado, involuntariamente, a terceiros - no caso, a destruição precoce de uma vida humana precipitada pelo fato de alguém dirigir alcoolizado. Desse modo, a sessão terapêutica parece ter permitido que ele se aproximasse dos riscos psicossociais do alcoolismo. Ao poder se identificar com a história narrada por outro participante e se deixar permear emocionalmente pelas ressonâncias que esse drama teve em sua própria subjetividade, Fernando permitiu-se reelaborar significados produzidos no espaço terapêutico frente aos seus próprios conflitos, o que o levou a se reposicionar subjetivamente.

Também me comovi bastante, porque fui uma pessoa que tive esse problema e hoje eu tenho conhecimento que passei pelo processo da doença, mas, buscando a Deus, a terapia e o programa de Alcoólicos Anônimos, eu estou uma pessoa 
liberta dessa doença do alcoolismo. Não estou curado, tenho consciência disso, mas hoje eu vi que, se eu tivesse continuado a beber, eu também poderia ter levado alguém à morte, ceifar a vida de pessoas que não tinham nada a ver com a minha problemática do alcoolismo.

Como se pode depreender por essa narrativa, durante a sessão, Fernando teve oportunidade de rever sua relação anterior com o álcool e ampliar suas concepções a respeito do alcoolismo. No próximo excerto de fala, o participante capta outro componente crucial do potencial terapêutico da TC: a possibilidade de generalização da experiência emocional, intensamente vivida durante a reunião grupal, para outros contextos de vida(17).

Alguma coisa que eu aprendo aqui, eu sempre aplico no cotidiano da minha vida. Como essa de hoje, que mostrou o mal que faz pros outros a bebida. Eu guardei isso da terapia. E algumas vezes que eu puder, eu posso passar pra alguém, dizer que aqui tem essa condição de se libertar dos vícios.

A percepção das consequências nefastas que a perda trágica teve para a família do rapaz, prematuramente morto, estimulou-o a valorizar o AA, a terapia e sua fé, fortalecendo sua convicção em relação à consistência de sua mudança pessoal.

Eu passei dez anos pelo mundo da droga, do álcool, a droga maior do mundo... o pessoal critica muito droga pequena, mas a droga maior do mundo é o álcool, que ceifa muitas vidas... Me senti muito triste, mas, ao mesmo tempo, depois, com as mensagem que foram faladas, as palavras reconfortantes para a mãe e o pai, eu me senti mais calmo.

O problema que, até então, possivelmente era percebido como circunscrito apenas à vida privada e à esfera individual, passou a fazer parte de subjetividade compartilhada, a partir da percepção do intenso sofrimento vivido pelo outro. Nesse contexto, a alteridade pode ser percebida e significada a partir da própria subjetividade. A subjetividade, por sua vez, é elemento constitutivo da alteridade presente na relação entre os indivíduos que se dispõem a compartilhar sua dor na roda de conversa, tornando-a, de certo modo, uma dor comum, humana, comunitária.

\section{A TC como recurso de apoio social na abordagem dos problemas relacionados ao uso de álcool}

As interações promovidas pela terapia, por meio da fala, gestos e atitudes, orações e músicas, encorajaram o participante a refletir sobre sua trajetória pessoal. Desse modo, puderam potencializar mudanças em sua autopercepção e em seu comportamento. O fato de, atualmente, reconhecer o álcool como "a droga maior do mundo" auxiliou Fernando a buscar cada vez mais sua autonomia em relação aos hábitos que alimentavam a dependência. Para tanto, foi necessário fortalecer sua autoestima e renovar diariamente a crença na possibilidade de superação da dependência do álcool. Para que as transformações sejam sustentáveis, é imprescindível contar com o apoio da comunidade. $\mathrm{Na}$ visão do participante, a terapia foi significada como importante fonte de apoio social.

Eu acho que aqui eu melhoro porque aqui, baseado nas coisas que eu vejo, os casos aqui, tudo é levado pra Deus. E quem vive com Deus, vive muito bem. Eu vim pra cá, faz um ano e pouco... Eu gostei, continuei vindo e me sinto muito bem, gosto das histórias, resgato a minha autoestima. Com essa terapia eu me sinto uma pessoa de bem, mais aproximada de Deus.

$\mathrm{O}$ relato de Fernando demonstrou seu reconhecimento de que o propósito da TC é promover o desenvolvimento de consciência crítica em relação à dependência de substâncias psicoativas, o que pode valer para qualquer outro tipo de dependência ou uso nocivo. A identificação do sofrimento que foi desencadeado pelo uso crônico de álcool e o despertar dessa consciência crítica foram os primeiros passos para a busca da superação. O participante se recordou da época em que bebia e das transformações pelas quais passou depois que começou a frequentar o AA e, em seguida, a TC:

Eu era uma pessoa muito difícil quando tava bebendo. $E_{,}$ antes de conhecer a terapia, eu cheguei a buscar Deus, mas aqui eu sinto mais aquela força... E passa de segunda a quartafeira, mas na quinta-feira tem a terapia... e eu tô lá. Me sinto bem mais à vontade quando eu assisto. Com mais paciência.. que eu sou muito explosivo. Às vezes eu fico assim, violento, então essa terapia tem me ajudado a frear meus instintos da explosão.

A percepção de benefícios auferidos pela terapia é evidenciada também na sequência desse mesmo relato.

Outra coisa melhor, que eu acho, é que a pessoa vem sentindo um problema e quando chega aqui encontra... e às vezes, naquela coisa que outra pessoa trouxe, eu passo alguma coisa ou recebo alguma coisa. Então eu recebo energias positivas, vontade de vivenciar uma vida mais digna, com responsabilidade. Toda quinta-feira eu tenho esse compromisso, às vezes, mesmo sem condição financeira, eu tô aqui. Tenho esse compromisso de sempre estar aqui porque isso ajuda na minha base espiritual.

Segundo o relato do participante, a terapia possibilita o exercício reiterado da reflexão. Fernando percebeu que a experiência que vivenciava era contínua e cumulativa o que se aproxima da concepção de terapia como processo de desenvolvimento pessoal e não unicamente 
como recurso de cura, ou remissão de sintomas. Essa percepção é bastante elaborada e pode estar relacionada à consciência de ser, ele próprio, um ser "inacabado", daí a necessidade de estar sempre crescendo e buscando se aperfeiçoar, transformando-se em pessoa melhor. Essas reflexões se aproximam da noção de "inacabamento do ser humano"(10), considerando que a inconclusão é própria da experiência vital. Em todo ser vivo há um inacabamento, mas somente na condição humana, isto é, entre mulheres e homens, o inacabamento se torna consciente. A linguagem, a cultura, a comunicação do ser humano, em níveis mais profundos e complexos, do que aquela que ocorre com os animais, possibilitam a "espiritualização" do mundo, o desenvolvimento da capacidade de comparar, ponderar, decidir, romper barreiras e estereótipos(10). O aperfeiçoamento dessas habilidades permite a intervenção no mundo, inscrevendo mulheres e homens como seres éticos, como disse Fernando a respeito de seu "compromisso" com a terapia, que é um compromisso de sempre estar aqui porque isso ajuda na minha base espiritual.

Nesse sentido, propôs-se que a terapia seja concebida como lugar de encontro do homem consigo mesmo e com os outros, em uma dimensão ética e existencial que é sua morada. Um espaço de transformação para que possa se encontrar com a alteridade e desenvolver o papel de protagonista de sua própria história. Desse modo, o homem é visto como ator social que se apropria de valores que precisam ser resgatados, principalmente na condição de ser fragilizado e que se sente excluído de possibilidades em seu devir, como é o caso do usuário abusivo de álcool. Na fala de Fernando, percebeu-se que a terapia, ao colocá-lo em contato profundo com seus pares, criou condições para que ele refletisse a respeito de sua posição frente à vida, assim como na relação com o outro, com as pessoas de sua comunidade: essa de hoje que mostrou o mal que faz pros outros a bebida. Eu guardei isso da terapia. Por essa via, ele se sensibilizou e se tornou mais consciente do próprio poder e, então, pôde aprofundar a visão que tinha de si mesmo e de seu agir, por meio da reelaboração e ressignificação de suas experiências de vida. Me sinto bem mais à vontade quando eu assisto. Com mais paciência, que eu sou muito explosivo. Às vezes eu fico assim, violento, então essa terapia tem me ajudado a frear meus instintos da explosão.

Ao compreender o processo de transformação em que está imerso, o participante pôde ressignificar sua trajetória de sofrimento, alimentada por anos a fio pelo alcoolismo, transformando-a em potencial de ajuda aos outros. E algumas vezes que eu puder eu posso passar pra alguém, dizer que aqui tem essa condição de se libertar dos vícios. Desse modo, poderá desenvolve seu senso de cidadania e ampliar seu processo de gradual reinserção social.

Na opinião de Fernando, a pessoa que frequenta a terapia constrói vínculos, ao mesmo tempo em que fortalece suas potencialidades, no sentido do empoderamento. O conceito de empoderamento se refere à estratégia que constitui eixo central do ideário que sustenta o projeto de promoção à saúde,enquanto resposta aos desafios sanitários contemporâneos ${ }^{(18)}$. Desse modo, a TC pode ser vista como filosofia e prática de cuidado que tem pressupostos afinados com esse ideário.

A palavra terapia vem do grego therapeia, que significa acolher, ser hospitaleiro e caloroso, servir, atender. Mas há, ainda, outra acepção, uma dimensão sagrada que possibilita às pessoas ressignificarem seu sofrimento e sua vida. O processo terapêutico permite saírem do sofrimento sem sentido para construírem algo novo. De fato, é comum se constatar inúmeros testemunhos de pessoas que chegaram à terapia com um drama pessoal aparentemente insolúvel e que saíram com um novo olhar, que promove maior autoconfiança e oferece centelha de esperança. Por essa ótica, a terapia é processo de transformação, de transmutação do ser, um espaço no qual cada pessoa pode ressignificar seu sofrimento, de acordo com uma nova leitura dos elementos que o faziam sofrer ${ }^{(7)}$.

Pelo fato de oferecer possibilidades de transformar sofrimento em crescimento, carência em competência, a TC é considerada pelo participante como espaço sagrado. De fato, tanto nas entrevistas como nas observações realizadas, constatou-se que a TC, na percepção do participante, está intrinsecamente ligada a questões de fé, embora nas sessões não seja professada a adesão a qualquer crença espiritual, tendo em vista que se adota o paradigma da diversidade. A possibilidade de conviver com diferenças de credo e ideologias, com abertura à pluralidade de expressões e crenças da comunidade, é elemento crucial da TC desde sua origem.

\section{Considerações finais}

No presente estudo, buscou-se compreender as potencialidades da TC como recurso de apoio social no enfrentamento de problemas relacionados ao uso de álcool. Viu-se que, na perspectiva do participante, a terapia constitui estratégia efetiva na abordagem dos problemas psicossociais, associados ao uso de álcool, pois leva ao empoderamento pessoal e comunitário 
que contribui para fortalecer os vínculos e a reinserção social. Participar da terapia estimulou o participante a buscar o autoconhecimento e formar vínculos sociais significativos. A partilha de experiências, durante o ritual das sessões, promoveu clima terapêutico de aceitação e escuta dos problemas, o que permite ao sujeito expressar seu sofrimento e compartilhar um conjunto de estratégias de superação que emergem da experiência cotidiana do grupo. Essa troca proporcionou a ressignificação de problemas compartilhados pelo participante com os demais integrantes da TC e a busca de soluções, socialmente partilhadas e adequadas ao contexto cultural, no qual a pessoa está inserida.

Como principal limitação do presente estudo podese apontar o fato de que os resultados são derivados de uma única entrevista, o que restringe as possibilidades de investigar outras nuances da aplicação da TC como recurso na abordagem do problema de abuso do álcool.

Concluiu-se que a TC, em associação com outros métodos complementares de suporte social e atividades socioeducativas, favoreceu no participante investigado compreensão ampliada de seus problemas decorrentes do uso crônico de álcool. Na perspectiva desse usuário, a partir de sua inserção na terapia, foi possível ressignificar suas experiências de vida e se organizar melhor a partir de seus próprios recursos.

O diálogo estabelecido promoveu ressignificação da problemática e redirecionamento do itinerário terapêutico no sentido da gestão da própria vida, exercício da autonomia e busca da cidadania. Tal avanço foi facilitado a partir de nova possibilidade de leitura dos problemas que eram, direta ou indiretamente, relacionados ao uso de álcool.

Considera-se que a abordagem do problema, em um contexto de saúde comunitária, permitiu ao participante encontrar alternativas viáveis de mudança nos seus hábitos de vida, conscientizando-se da necessidade de se responsabilizar por seu autocuidado e assumir os rumos de sua própria história. Nesse cenário, resguardados os limites da presente investigação, os resultados sugerem que a TC pode ser estratégia alternativa para a abordagem dos problemas de uso abusivo do álcool no campo da atenção primária.

\section{Agradecimentos}

Agradecemos a Comissão Interamericana para o Controle do Abuso de Drogas/CICAD da Secretaria de Segurança Multidimensional/SSM da Organização dos Estados Americanos/OEA, a Secretaria Nacional de Políticas sobre Drogas/SENAD do Gabinete de Segurança Institucional/Brasil, a Escola de Enfermagem de Ribeirão Preto da Universidade de São Paulo e o Centro Colaborador da Organização Mundial da Saúde para o Desenvolvimento da Pesquisa em Enfermagem, a população representada nas pesquisas, bem como as autoridades das universidades representadas pelos participantes do Programa On-Line de Especialização em Pesquisa sobre o Fenômeno das Drogas, períodos 2006, 2007, 2008 e 2009.

\section{Referências}

1. Pratta EMM, Santos MA. Adolescence and the consumption of psychoactive substances: the impact of the socioeconomic status. Rev. Latino-Am. Enfermagem. 2007;15(número especial):806-11.

2. Luis MAV, Lunetta ACF. Álcool e outras drogas: levantamento preliminar sobre a pesquisa produzida no Brasil pela enfermagem. Rev. Latino-Am. Enfermagem. 2005:13(número especial):1219-30.

3. Vargas D., Luis MAV. Development and validation of a scale of attitudes towards alcohol, alcoholism and alcoholics. Rev. Latino-Am. Enfermagem. 2008:16(5):895-902.

4. Reinaldo AMS, Pillon SC. Alcohol effects on family relations: a case study. Rev. Latino-Am. Enfermagem. 2008;16(número especial):529-34.

5. Jinez LJ, Souza JRM, Pillon SC. Drug use and risk factors among secondary students. Rev. Latino-Am. Enfermagem. 2009;17(2):246-52.

6. Barroso T, Mendes A, Barbosa A. Analysis of the alcohol consumption phenomenon among adolescents: study carried out with adolescents in intermediate public education. Rev. Latino-Am. Enfermagem. 2009;17(3):347-53.

7. Barreto AP. Terapia Comunitária: passo a passo. Fortaleza: LCR; 2005.

8. Luisi LVV. Terapia Comunitária: bases teóricas e resultados práticos de sua aplicação. [dissertação]. São Paulo (SP): Pontifica Universidade Católica de São Paulo/ PUCSP; 2006.

9. Guimarães FJ, Ferreira Filha MO. Repercussões da terapia comunitária no cotidiano de seus participantes. Rev Eletr Enferm. 2006;8(3):404-14.

10. Freire P. Pedagogia da autonomia. Rio de Janeiro (RJ): Paz e Terra; 1997.

11. Biasoli-Alves ZM, Romanelli G., organizadores. Diálogos metodológicos sobre prática da pesquisa. Ribeirão Preto (SP): Legis Summa; 1998. 
12. Geertz C. A interpretação das culturas. Rio de Janeiro

(RJ): Guanabara-Koogan; 1989.

13. Geertz C. O saber local: novos ensaios em antropologia interpretativa. $3^{a}$ ed. Petrópolis (RJ): Vozes; 2000.

14. Damatta R. Relativizando: uma introdução à antropologia social. Rio de Janeiro (RJ): Rocco; 1987.

15. Minayo MCS. O desafio do conhecimento: pesquisa qualitativa em saúde. $8^{a}$ ed. São Paulo (SP): Hucitec/ Abrasco; 2004.

16. Demo P. Metodologia do conhecimento científico. São Paulo (SP): Atlas; 2000.

17. Bechelli LPC, Santos MA. O paciente na psicoterapia de grupo. Rev. Latino-Am. Enfermagem. 2005;13(1):11825.

18. Carvalho SR. Os múltiplos sentidos da categoria empowerment no projeto de Promoção à Saúde. Cad Saúde Pública 2004;20(4):1088-95. 